\title{
ABC Algorithm Based PID Controller Design for Higher Order Oscillatory Systems
}

\author{
Aytekin Bagis, Halit Senberber \\ Department of Electrical \& Electronics Engineering, Faculty of Engineering, Erciyes University, \\ 38039, Kayseri, Turkey \\ halitsenberber@erciyes.edu.tr
}

\begin{abstract}
This paper presents the results of an investigation based on the use of artificial bee colony (ABC) algorithm to determine the optimum PID parameters for higher order oscillatory systems. For this aim, several oscillatory systems with different orders from the literature were selected. In order to achieve the desired closed loop system response, the PID parameters were tuned by the $A B C$ algorithm using an appropriate objective function. To demonstrate the effectiveness of the considered approach, performance of the $A B C$ algorithm was compared with that of the conventional PID tuning methods given in the literature and two popular heuristic optimization algorithms namely particle swarm optimization (PSO) algorithm and genetic algorithm (GA).
\end{abstract}

Index Terms-Artificial bee colony algorithm; PID controller design; PID tuning, population based metaheuristics.

\section{INTRODUCTION}

In the design of the control systems, ProportionalIntegral-Derivative (PID) type controllers have an exclusive and important position. To achieve a desired system response, the controller parameters should be carefully determined by an appropriate tuning approach. For higher order and/or oscillatory systems with complex dynamics, this operation can be quite difficult and time-consuming. The performance of the designed control system is directly affected by various main factors such as the definition of an acceptable process model, consideration of the time or frequency domain for the controller design, selection of a suitable objective function for control purposes, or determination of a controller tuning method.

There are many classical approaches and methods in the literature which use the time or frequency domain response of the systems [1]-[17]. On the other hand, by using PID tuning approaches based on artificial intelligence optimization algorithms such as genetic algorithms (GAs) [18]-[21], the tabu search algorithm (TSA) [22], [23], differential evolution algorithm (DEA) [20], [24], ant colony optimization algorithm [25], particle swarm optimization (PSO) [26]-[28], and the artificial bee colony (ABC) algorithm [29], fast and efficient control solutions can be obtained. Wang and Kwok presented a GA based PID tuning study for a $\mathrm{pH}$ neutralization process [21]. In the study reported by Saad et al. [20], to achieve the optimal

Manuscript received 2 March, 2017; accepted 15 September, 2017.

This work was supported by Research Fund of the Erciyes University. Project Number: FBA-2015-6236.
PID parameters, GA and DEA approaches are comparatively used for three different systems namely high order, with time delay and the non-minimum phase. The study presented in [20] considers the values of mean squared error (MSE) and the integral of absolute error (IAE) for performance evaluation of these algorithms.

In the study of Bagis [18], a modified GA based approach is used for optimal PID parameters. Karaboga and Kalinli [23] employed the TSA to find the PID parameters for a given process. In a study by Bagis and Savascihabes [24], the PID tuning operation is performed by the DEA for the desired closed loop system response. A PSO based application for robust PID controller design is given by Zhao et al. [28]. Chang and Shih [27] presented a PID controller design method for nonlinear systems by using an improved PSO approach based on modified velocity and position updating equations. In another study on the PSO algorithm, useful information on algorithm performance was obtained in the modelling problem of high order oscillatory systems [30]. In this conference paper presented by Bagis, in order to define the five different high order processes, the parameters of three different model structures are determined by a typical PSO algorithm. Karaboga and Akay reported a comparison of the $\mathrm{ABC}$ algorithm, harmony search, and the bees' algorithms for the PID design problem [29].

The main aim of this study is to investigate the performance of the $\mathrm{ABC}$ algorithm to solve a difficult controller design problem based on the use of the PID controller. Another key contribution of this paper is that it examines the main idea of how the $\mathrm{ABC}$ algorithm can be used as an efficient alternative and/or supportive approach to improve the performance of the system under control. At this, several oscillatory systems with different orders in the literature were selected. The performance of the ABC algorithm was compared with those of the conventional PID tuning methods given in the literature and two popular heuristic optimization algorithms, namely the PSO and GA.

The definition of the PID control problem for the ABC algorithm based controller design is given in Section II. In Section III, the ABC, GA and PSO algorithms and the control parameters used in this study are briefly presented. The comparison of simulation results is given in Section IV. Discussion and conclusion are given in the last sections.

\section{PID DESIGN PROBLEM}

The basic principle in PID tuning is to adjust the 
controller parameters fast and accurately as possible for aims of the control design. These parameters are entitled by proportional tuning constant, $\mathrm{Kp}$, integral tuning constant, $\mathrm{Ki}$, and derivative tuning constant, Kd. For a typical PID controller, the controller output signal $\mathrm{u}(\mathrm{t})$ can be written as the following in time and s domain [18]:

$$
\begin{gathered}
u(t)=K p \times e(t)+K i \times \int_{0}^{t} e(t) d t+K d \frac{d e(t)}{d t} \\
U(s)=\left(K p+\frac{K i}{s}+K d \times s\right) \times E(s)
\end{gathered}
$$

where $e(t)$ is the error signal, and calculated by difference between the reference input, $r(t)$, and system output, $y(t) ; s$ is a complex variable which has a real part and an imaginary part. The variables of $s$ and $(1 / s)$ in (2) can be considered as differential and integral operators in time domain, respectively. It is a well-known fact that parameter tuning approach directly affects behaviour of the PID controller and satisfactoriness of the control system designed for the control aims. Therefore, in order to meet the desired closed loop system specifications in time and/or frequency domain, PID controller parameters must be carefully determined. For this purpose, one of the efficient approaches is to use the specifications of the system's step response. Thus, a controller design strategy that provides the aims of the control system can be proposed by analysing the step response of the controlled system. Definition of an appropriate objective function based on the use of important performance indicators such as the overshoot, settling time, and the integral time absolute error (ITAE) value can provide the remarkable solutions for the controller tuning.

In this study, an $\mathrm{ABC}$ algorithm based design mechanism for PID control of higher order oscillatory systems is proposed as shown in Fig. 1.

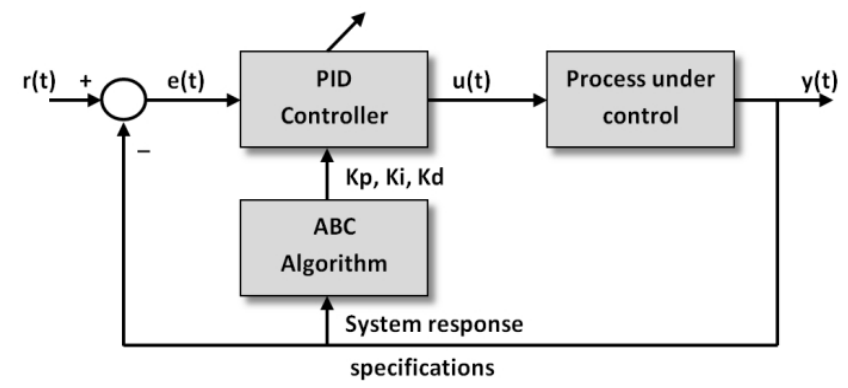

Fig. 1. PID tuning by using $\mathrm{ABC}$ algorithm.

The main purpose of the algorithm is to tune the parameters of the PID controller by using an objective function (OF) given in (3). This equation comprise of a combination of the ITAE, percent maximum overshoot $(\mathrm{OS})$, and 5 percent settling time $(t s)$

$$
O F=10 \times I T A E+5 \times t s+3 \times O S .
$$

In this function, ITAE performance index is described as

$$
I T A E=\int_{0}^{T} t \times|e(t)| d t
$$

As mentioned earlier, the main contribution and motivation of this work is in exploring the results of the
$\mathrm{ABC}$ algorithm having an efficient objective function for controlling the higher order systems. The similar structures to this function type were used in our previous studies, and impressive results were obtained [18], [19], [22], [24]. Thus, it is preferred to use such a weighted objective function that is formed different performance specifications. In this study, because minimization of the ITAE value is primarily aimed in the step response of the closed loop system under control action, the coefficient of this performance index was selected as 10 .

\section{AlgORIthMS USED IN STUDY}

\section{A. ABC Algorithm}

One of the quite successful optimization algorithms is the artificial bee colony (ABC) algorithm presented by Karaboga [29], [31]-[33]. This population based approach presents efficient solutions for numerical optimization problems especially. In main procedure of the algorithm, foraging behaviours of bee colonies are simulated by three groups of the bees. These are employed, onlooker, and scout bees. Locations of food sources are evaluated as possible solutions for the problem. The possible and new solutions are determined by the employed bees. Nectar amounts (fitness values) in the food sources define the qualities of the solutions. The new possible food sources are selected by the onlooker bees according to information of nectar amounts. Selection procedure of the scout bees is controlled by an important control parameter called "limit" which is the value of predetermined number of cycles.

To improve the quality of the solution, generally, a mathematical description is used by the algorithm as the following [32], [33]

$$
V_{i j}=X_{i j}+\operatorname{rand}(-1,1)\left(X_{i j}-X_{k j}\right)
$$

This description denotes the location of the new possible sources with more quality according to a nectar source in the position $i$. In here, $k(k \in\{1,2, \ldots . .$, pop_size $\})$ a randomly chosen index that has to be different from $i$ and $j$ are randomly selected indice. In here, $V_{i j}, X_{i j}$ and $X_{k j}$ are new, current and neighbor solutions, respectively.

There are also two important control parameters that directly impress the performance of the algorithm: colony size and the number of the maximum cycles. In this paper, for the limit value, description of $[($ colony size $\div 2) \times$ number of the parameters] is used.

\section{B. PSO Algorithm}

PSO presented by Kennedy and Eberhart [34], [35] is a population based stochastic optimization algorithm [26][28], [30]. In the algorithm, there is possible solution elements called as particles in the population. During the search procedure, solution quality is improved by altering the positions and velocities of the particles. Best values for the particles and swarm are kept by the algorithm for use when needed. PSO approach has a simple and flexible structure.

New position (x) and velocity (v) values for the $i^{\text {th }}$ particle are generally obtained by using the descriptions in (6)-(7) [26]-[28], [30]. In these equations, $k$ is the currently 
iteration number, and $w$ is the inertia weight factor. The best position values for the particles and swarm are represented by $\mathrm{P}$ and $\mathrm{G}$ symbols. Cognitive and social parameters are specified with the constants of $c_{1}$ and $c_{2}$, respectively. Random variables of $r_{1}$ and $r_{2}$ are in the interval of [0-1]. The variables of $v$ and $x$ are (population size $\times$ optimized parameters number)-dimensional vectors. In this study, the size of these vectors is $(30 \times 3)$ :

$$
\begin{gathered}
v_{i}(k+1)=w_{i} \times v_{i}+c_{1} \times r_{1} \times \\
\times\left(P_{i}-x_{i}(k)\right)+c_{2} \times r_{2} \times\left(G-x_{i}(k)\right), \\
x_{i}(k+1)=x_{i}(k)+v_{i}(k+1) .
\end{gathered}
$$

\section{Genetic Algorithm (GA)}

Population based GAs are one of the general-purpose search algorithms [18]-[21], [31]. The population consists of chromosomes which represent the possible solutions for the problem. To obtain fitness values or qualities of the chromosomes, an appropriate objective or cost function called as fitness function is used. The fitness function is an important and critical performance index to describe the qualities of each individual in the population. The qualities and diversities of the solutions in the population are improved by using some critical procedures such as reproduction, crossover and mutation. The number of transfer to the next generation of the most fits chromosomes in the populations is controlled by reproduction operation.

In solving a specific optimization problem, some critical decisions such as genetic representation of the solutions, selection mechanism, description of the fitness function, and determination of the control parameters are performed by the GA. In this study, the real coded GA with roulette wheel selection operator is used the single point crossover operation. The fitness values for the chromosomes are obtained by using the definition of " $100 /(1+$ objective function value)".

\section{EXPERIMENTAL RESULTS}

For the PID tuning problem, various higher order oscillatory systems from the literature were considered as the following [36]-[38]:

$$
\begin{gathered}
G_{1}(s)=\frac{1}{\left(s^{2}+s+1\right)(s+2)^{2}} e^{-0.1 s}, \\
G_{2}(s)=\frac{1}{(s+1)^{6}\left(s^{2}+2\right)}, \\
G_{3}(s)=\frac{1}{\left(s^{2}+2 s+3\right)^{3}(s+3)} e^{-0.3 s} .
\end{gathered}
$$

The G1, G2, and G3 systems given in (8)-(10) are investigated in [37], [38], [37], and [36], [38], respectively. In this study, the control parameters for the algorithms are selected and are given in Table I. In order to obtain the most

\begin{tabular}{|c|c|c|c|}
\hline Control Parameter & PSO & GA & $\mathbf{A B C}$ \\
\hline Population (or colony) size & \multicolumn{3}{|c|}{30} \\
\hline Cognitive and social parameters & $\mathrm{c} 1=\mathrm{c} 2=2$ & - & - \\
\hline Limit & - & - & 45 \\
\hline Crossover and Mutation Rate & - & $\begin{array}{c}0.9 / \\
0.3 \\
\end{array}$ & - \\
\hline Number of Generation (maxit) & \multicolumn{3}{|c|}{100} \\
\hline Inertia weight factor & $\begin{array}{l}\mathrm{W}=(\mathrm{maxit}- \\
\text { iteration }) / \text { maxit }\end{array}$ & - & - \\
\hline $\begin{array}{l}\text { Parameter Search } \\
\text { Interval for PID }\end{array}$ & \multicolumn{3}{|c|}{$[0-100]$} \\
\hline
\end{tabular}
efficient parameters, many trials were made by using the trial-and-error method and our previous experiences of heuristic algorithms. Thus, the values in Table I that provide the minimized objective functions were obtained.

TABLE I. CONTROL PARAMETER VALUES.

The PID tuning procedure based on the ABC, PSO and GA was repeated as 30 times for 100 iterations in each system. To present the efficiency of the ABC approach, search intervals for the PID parameters were preferred in the intervals of [0-100]. The simulation times for the $\mathrm{G} 1$ and $\mathrm{G} 3$ processes were used in the interval of [0-50] s. On the other hand, this period for process G2 was taken as [0100] s. In the simulation, the Matlab programming package [39], [40] and a Mobile Intel Core i7, $2400 \mathrm{MHz}$ computer were used.

The optimum PID parameters obtained by the algorithms for the considered processes are given in Table II. In this table, the step response specifications of the PID controlled systems are also given. As shown in Table II, these results are compared with different methods in the literature [36] [38]. For this purpose, the time response values of the systems under PID control, based on the use of PID parameters in the related references, are calculated by using the Matlab program. The time responses of the systems controlled by different methods are also plotted in Fig. 2 .

It is clearly shown in Table II that the values of the PID controllers optimized by the algorithms are very close to each other. Thus, the step responses of the algorithm based systems are inherently very similar. Therefore, the drawing of the $\mathrm{ABC}$ algorithm based system response alone is shown in Fig. 2. From Table II, it can be clearly seen that the optimum PID controller parameters obtained by the algorithms are almost identical to each other for all the processes. From Table II again, the performance of the $\mathrm{ABC}$, PSO and GAs is quite impressive. The desired values of the step response specifications are strikingly achieved by the ABC, PSO and GA based PID controllers. In particular, this case can be distinguished from the ITAE and settling time values obtained by the algorithm based systems.

In the design of a PID control system, some important preferences such as fast control with a large overshoot or slow control with no overshoot can be made inevitably. Fortunately, using the presented $\mathrm{ABC}$, PSO and GA approaches, settling time and overshoot can be concurrently decreased as compared to other methods. It is possible that the significant improvements on the controlled system response can be achieved by performing the required modifications in the objective function.

It can be seen from Table II and Fig. II that the $\mathrm{ABC}$, PSO and GA based systems show a considerable improvement in the values of ITAE, settling time, and maximum overshoots for all the processes. 
TABLE II. PID CONTROLLER PARAMETERS [36]-[38] AND STEP RESPONSE SPECIFICATIONS.

\begin{tabular}{|c|c|c|c|c|c|c|}
\hline \multirow[b]{2}{*}{$\mathbf{P r}$} & \multirow{2}{*}{ Method } & \multirow{2}{*}{$\begin{array}{c}\begin{array}{c}\text { PID } \\
\text { Parameters }\end{array} \\
\mathbf{K p}, \\
\mathbf{K i}, \\
\text { Kd } \\
\end{array}$} & \multicolumn{4}{|c|}{ Step response specifications } \\
\hline & & & ITAE & ts & OS \% & OF \\
\hline \multirow{7}{*}{ G1 } & $\begin{array}{c}\text { Malwatkar } \\
\text { et al. [37] }\end{array}$ & \begin{tabular}{|l|}
1.3039 \\
1.3104 \\
1.3351 \\
\end{tabular} & 6.1999 & 6.2875 & 0.3143 & 94.3796 \\
\hline & $\begin{array}{c}\text { Wang et al. } \\
{[38]}\end{array}$ & $\begin{array}{l}1.5030 \\
1.3660 \\
1.7150 \\
\end{array}$ & 6.1833 & 6.6230 & 0.6808 & 96.9898 \\
\hline & $\begin{array}{c}\text { Ho et al. } \\
{[38]}\end{array}$ & $\begin{array}{l}2.1470 \\
1.4840 \\
0.7770 \\
\end{array}$ & 7.2006 & 9.4044 & 3.5306 & 129.620 \\
\hline & $\mathbf{Z N}$ & $\begin{array}{l}4.2331 \\
1.6277 \\
2.7522\end{array}$ & 8.0067 & 11.6359 & 2.4391 & 145.564 \\
\hline & PSO & $\begin{array}{l}2.7106 \\
2.2147 \\
2.8134 \\
\end{array}$ & 2.6440 & 3.1886 & 1.8618 & 47.9686 \\
\hline & GA & $\begin{array}{l}2.7131 \\
2.2389 \\
2.8597\end{array}$ & 2.6312 & 3.1698 & 1.9619 & 48.0472 \\
\hline & $\mathbf{A B C}$ & $\begin{array}{l}.7121 \\
2.2136 \\
2.8118 \\
\end{array}$ & 2.6452 & 3.1883 & 1.8582 & 47.9683 \\
\hline \multirow{7}{*}{ G2 } & $\begin{array}{c}\text { Malwatkar } \\
\text { et al. }[37]\end{array}$ & $\begin{array}{c}0.78 \\
0.3708 \\
0.8964 \\
\end{array}$ & 69.269 & 20.782 & 16.257 & 845.37 \\
\hline & $\begin{array}{c}\text { Wang et al. } \\
{[37]}\end{array}$ & $\begin{array}{c}0.5996 \\
0.6299 \\
2.281 \\
\end{array}$ & 216.52 & 53.313 & 48.14 & 2576.16 \\
\hline & $\begin{array}{c}\text { Ho et al. } \\
\text { [37] }\end{array}$ & $\begin{array}{c}1.959 \\
0.5727 \\
1.676\end{array}$ & 48.045 & 23.778 & 30.106 & 689.66 \\
\hline & $\mathbf{Z N}$ & $\begin{array}{l}.3702 \\
0.4356 \\
3.2245 \\
\end{array}$ & 29.329 & 21.716 & 14.466 & 445.27 \\
\hline & PSO & $\begin{array}{c}1.9742 \\
0.4919 \\
3.033\end{array}$ & 23.575 & 13.058 & 4.9997 & 316.04 \\
\hline & GA & $\begin{array}{l}1.9814 \\
0.4943 \\
3.0328 \\
\end{array}$ & 23.554 & 13.060 & 5.3497 & 316.89 \\
\hline & $\mathbf{A B C}$ & $\begin{array}{l}1.9738 \\
0.4923 \\
3.0306 \\
\end{array}$ & 23.576 & 13.055 & 5.0021 & 316.04 \\
\hline \multirow{7}{*}{ G3 } & $\begin{array}{c}\text { Kappa- } \\
\text { Tau } \\
{[36]}\end{array}$ & $\begin{array}{c}4.51 \\
0.9756 \\
0.1485\end{array}$ & 38.0459 & 16.6627 & 0 & 463.7730 \\
\hline & $\begin{array}{c}\text { Karimi } e t \\
\text { al. }[36]\end{array}$ & $\begin{array}{c}4.93 \\
15.6013 \\
0.6162 \\
\end{array}$ & 15.6880 & 8.6716 & 0.6982 & 202.3331 \\
\hline & $\begin{array}{c}\text { Wang et al. } \\
{[38]}\end{array}$ & $\begin{array}{c}17.562 \\
22.485 \\
14.13\end{array}$ & 10.0070 & 9.1222 & 5.1766 & 161.2102 \\
\hline & $\mathbf{Z N}$ & $\begin{array}{c}3.1985 \\
14.37 \\
32.465 \\
\end{array}$ & 35.1072 & 22.8617 & 0.6884 & 467.446 \\
\hline & PSO & $\begin{array}{l}29.177 \\
25.729 \\
20.632 \\
\end{array}$ & 6.0179 & 4.6798 & 1.3326 & 87.576 \\
\hline & GA & $\begin{array}{c}29.2213 \\
25.745 \\
20.7187 \\
\end{array}$ & 6.0178 & 4.6758 & 1.3585 & 87.633 \\
\hline & $\mathrm{ABC}$ & $\begin{array}{l}29.148 \\
25.706 \\
20.573\end{array}$ & 6.0205 & 4.6845 & 1.3162 & 87.576 \\
\hline
\end{tabular}

In particular, again for all processes, the best values for settling time are obtained by $\mathrm{ABC}$, PSO and GA based studies as compared with other approaches. Similarly, all the processes exhibit the best behavior in terms of ITAE. As seen in Table II, in the PID control of G2, the best (minimum) overshoot values are obtained. When the ABC algorithm is used, this value is $5.0021 \%$ for $\mathrm{G} 2$.

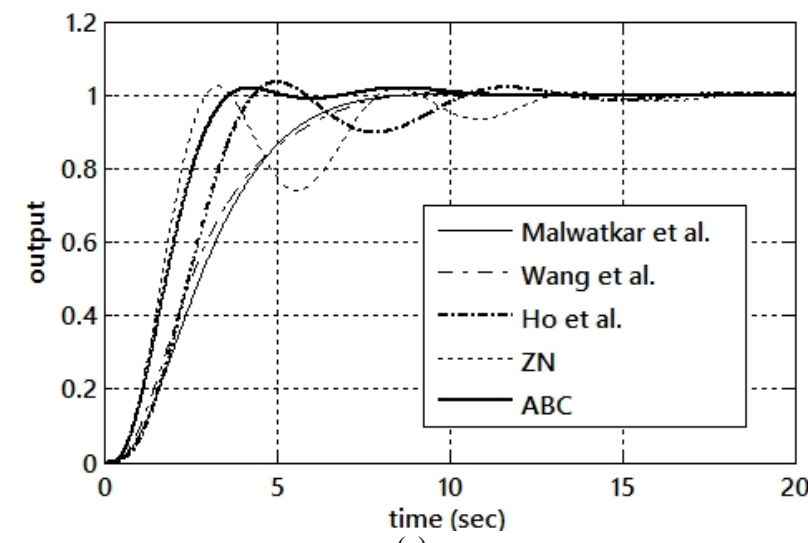

(a)

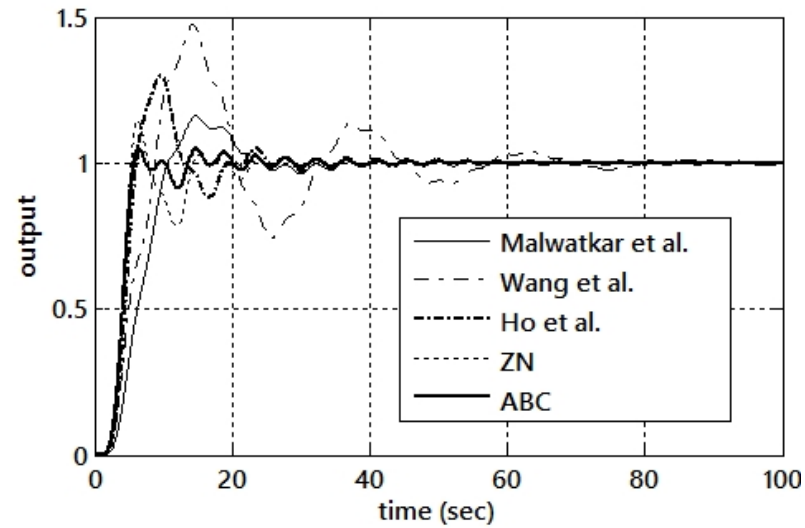

(b)

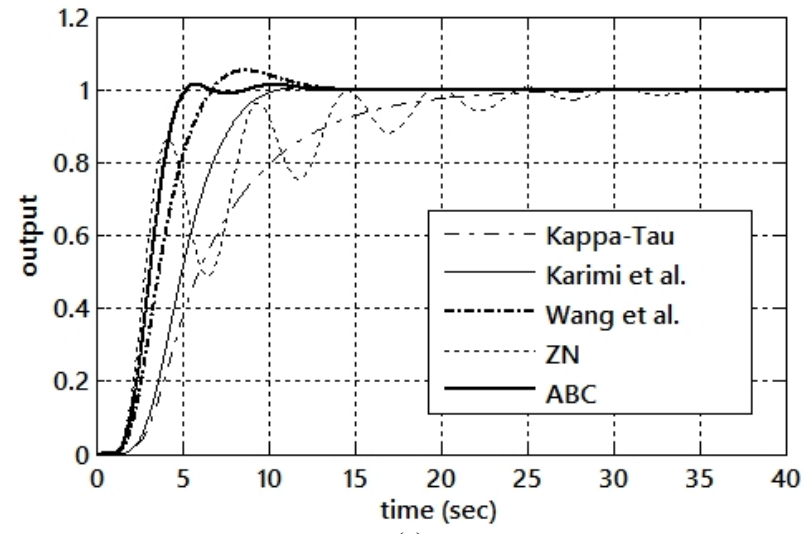

(c)

Fig. 2. Step responses of different methods for process: (a) G1(s), (b) G2(s), (c) G3(s).

In addition to other step response specifications, these striking reductions in the overshoots are clear indicators of the algorithm's power. On the other hand, although the maximum overshoots of the $\mathrm{ABC}$ method are not the best values for all the processes, these are quite satisfactory values when considering the long settling times of the other methods.

In this study, the time domain specifications of the PID controlled systems are considered for PID tuning based control system design. On the other hand, in frequency response based approaches, some important performance indicators such as sensitivity, gain and phase margin (GM, PM) values are often used [11]-[13], [16], [28], [40], [41]. 
In terms of the stability of the systems, two main sensitivity values are important. These are the maximum and maximum complementary sensitivities (Ms and Mp). Although these indicators do not exist in the objective function, the values of these robustness characteristics for PID controlled systems are also presented in Table III.

TABLE III. ROBUSTNESS CHARACTERISTICS OF PID CONTROLLED PROCESSES

\begin{tabular}{|c|c|c|c|c|c|}
\hline \multirow{2}{*}{ Pr } & \multirow{2}{*}{ Method } & \multicolumn{4}{|c|}{ Characteristic of Robustness } \\
\hline & & Ms & Мp & GM & PM (deg) \\
\hline \multirow{6}{*}{ G1 } & Malwatkar et al. [37] & 1.2843 & 0.9999 & 8.9310 & 70.0145 \\
\hline & Wang et al. [38] & 1.2534 & 0.9999 & 7.8182 & 71.9707 \\
\hline & Ho et al. $[38]$ & 1.7883 & 0.9998 & 2.7680 & 70.6715 \\
\hline & PSO & 1.5288 & 1.0000 & 4.3452 & 66.1671 \\
\hline & GA & 1.5265 & 1.0000 & 4.3428 & 65.8825 \\
\hline & $\mathbf{A B C}$ & 1.5294 & 1.0000 & 4.3426 & 66.1943 \\
\hline \multirow{6}{*}{ G2 } & Malwatkar et al. [37] & 1.6332 & 1.1247 & 4.1004 & 52.7666 \\
\hline & Wang et al. [37] & 2.7116 & 2.2370 & 4.8544 & 27.132 \\
\hline & Ho et al. [37] & 2.2397 & 1.4879 & 1.9991 & 45.358 \\
\hline & PSO & 1.9358 & 1.0010 & 2.1266 & 64.3008 \\
\hline & GA & 1.9417 & 1.0076 & 2.1200 & 64.1526 \\
\hline & $\mathbf{A B C}$ & 1.9363 & 1.0014 & 2.126 & 64.328 \\
\hline \multirow{6}{*}{ G3 } & Kappa-Tau [36] & 1.3449 & 1.0000 & 4.2933 & 72.5729 \\
\hline & Karimi et al. [36] & 1.5763 & 0.9999 & 3.0140 & 63.9997 \\
\hline & Wang et al. [38] & 1.5989 & 1.0020 & 3.1451 & 60.6215 \\
\hline & PSO & 1.7226 & 1.0000 & 2.4134 & 62.4362 \\
\hline & GA & 1.7236 & 1.0000 & 2.4104 & 62.4415 \\
\hline & ABC & 1.7228 & 0.9999 & 2.413 & 62.446 \\
\hline
\end{tabular}

In a robust system, as evidence of the system's relative stability, the values of the Ms and Mp parameters must be as low as possible [41]. As known, a large $\mathrm{Mp}$ in the frequency domain corresponds to a large overshoot in the step response. On the other hand, for a successful disturbance rejection behavior, the value of $\mathrm{Ms}$ should be low. In addition to this, in general, large gain and phase margins are desired system specifications.

In spite of the fact that the robustness specifications such as the minimum Ms and/or Mp values, and predetermined margin values are not in the features of the purposed system behaviors, we can say from Table III that the ABC, PSO and GA based PID controlled systems provide good robustness characteristics in general. For all of the processes, the measurements of the Ms, Mp, and phase margin can be considered as satisfactory values. However, admittedly, there clearly needs to be an improvement with regard to gain margin properties.

One of the main performance characteristics of the algorithm based methods is the computational time for the iterations. In this study, the search procedure for each of the processes was repeated 30 times for an iteration number of 100 by the ABC, PSO and genetic algorithms. When the $\mathrm{ABC}$ algorithm is used, the average calculation times for 100 iterations of the $\mathrm{G} 1, \mathrm{G} 2$, and $\mathrm{G} 3$ processes are noted as $500.54 \mathrm{sec}, 416.01 \mathrm{sec}$, and $474.27 \mathrm{sec}$, respectively. Similarly, these values for the same processes in the PSO based studies are obtained as $56.168 \mathrm{sec}, 46.751 \mathrm{sec}$, and $73.169 \mathrm{sec}$, respectively. Finally, the average calculation times for GA based studies are found as $39.52 \mathrm{sec}$, $21.69 \mathrm{sec}$, and $54.27 \mathrm{sec}$, respectively. These values clearly show that the computation time of the $\mathrm{ABC}$ algorithm is dramatically longer than those for the PSO and genetic algorithms. Admittedly this situation is a disadvantage of the $\mathrm{ABC}$ algorithm.

Furthermore, in order to demonstrate the convergence speed of the $\mathrm{ABC}$, PSO and genetic algorithms, the iteration-objection function (OF) variation curves of the PID controlled systems obtained by the algorithms for each process are given in Fig. 3.

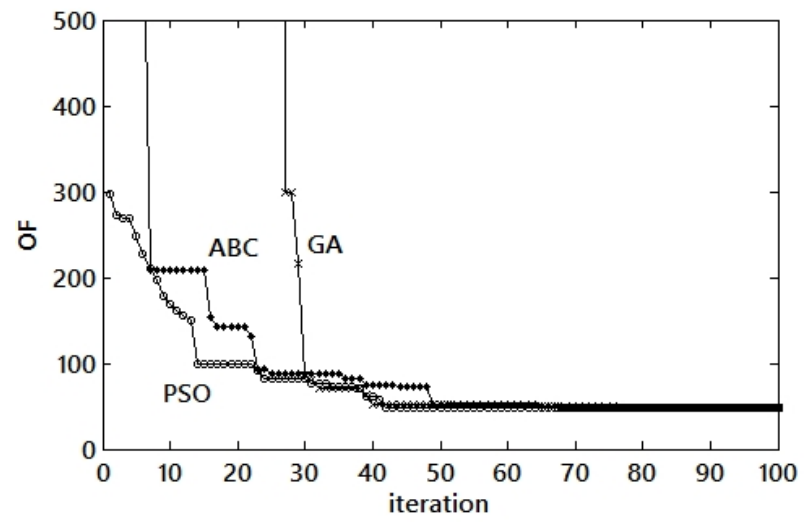

(a)

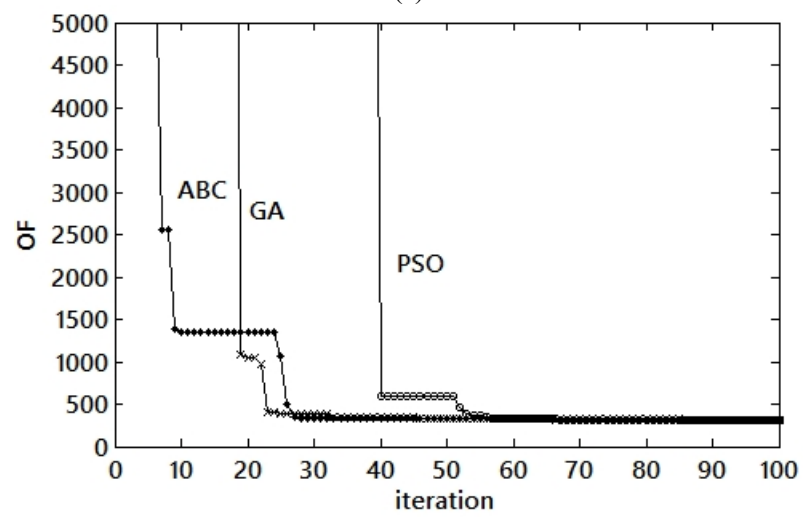

(b)

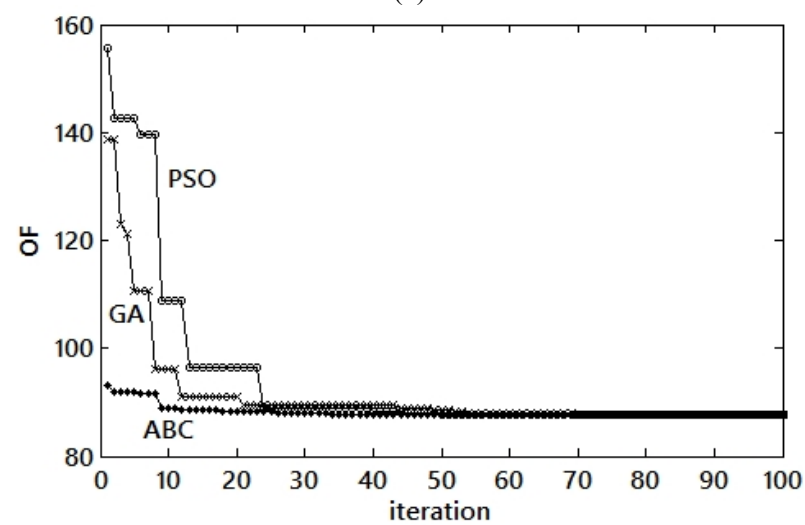

(c)

Fig. 3. Iteration-objection function (OF) variation curves of the systems obtained by the algorithms for each process: (a) G1(s), (b) G2(s), (c) G3(s).

Although the algorithm has a large search area given as [0-100], it can be seen from Fig. 3 that the ABC, PSO and GA methods are converged rapidly into the desired values of the objective function, requiring only 20-50 iterations. For the G2 and G3 processes, the convergence rate of the $\mathrm{ABC}$ algorithm is better than that of the PSO algorithm. However, the PSO algorithm in the G1 process needs fewer iterations for the best solution as compared with the ABC. On the other hand, the worst convergence performance for the G1 process is exhibited by the GA. In the G2 and G3 processes, 
the performance ranking in terms of convergence in a low number of iterations is observed as ABC, GA, and PSO. Nevertheless, from the simulation results, it can be observed that, especially in terms of the eventual best outcome obtained from the PID controlled systems, the ABC, PSO and GAs have similar ability and comparable convergence rates.

\section{DISCUSSION}

In this study, the performance of $\mathrm{ABC}$, PSO and GA approaches in the PID based control of the higher order oscillatory systems is investigated. For this research, a simple but effective objective function including the basic step response properties was used. The results of the simulations clearly show that all of these algorithms are extremely successful in identifying the PID parameters to achieve the desired control objectives. The GA that provides the shortest calculation times requires more control parameters and procedures to identify the problem. In addition, more iterations than the other algorithms are needed by the GA to achieve the minimum objective function value. In the PSO approach, which requires more parameters to be stored and updated when compared to the GA, good solutions are achieved with slightly longer calculation times. The calculation times in PSO are about 1.5 times higher than those in GA. In the PSO algorithm, as in GA, optimum PID parameters are obtained in high iterations. Unlike other algorithms, the appropriate PID parameters in the $\mathrm{ABC}$ approach can be provided in low iterations. Moreover, this algorithm has a simple structure consisting of few control parameters. This provides ease of application to the user. On the other hand, the most striking disadvantage of this algorithm is the long computation time which is 7-10 times higher than other algorithms.

According to the simulation results, a general summarization can be drawn as follows:

1. The main benefit of using the ABC algorithm based method is that the controller tuning can be easily done to perform the desired control objectives. Fast and easy reconfiguration of the algorithm structure or search procedure can be achieved by the users.

2. The simulations show that, as compared with the PSO and $\mathrm{GA}$, the $\mathrm{ABC}$ algorithm cannot rapidly reach optimal controller performance for kinds of higher oscillatory systems considered in this study. Also, to improve the quality of the solutions, the $\mathrm{ABC}$ algorithm needs long computation times in the iterations. However, the algorithm can provide the high improvements on the solutions for low iteration numbers. Furthermore, the ABC algorithm always provides the competitive outcomes with high quality.

On the other hand, an important advantage of the ABC algorithm is that it also has fewer control parameters than the PSO and genetic algorithms.

3. It is clear that the performance of the controlled systems depends directly on the type of objective function. For non-expert users, this property can provide a significant advantage. The advantage of the objective function used in this study is that the PID parameters can be adjusted effectively by modifying the adjustment coefficients for desired step response specifications.
4. In this study, to define the objective function, three main performance indicators in the time domain are preferred. There is no any robustness specification in the objective function. Thus, robustness characteristics provided perfectly by the controlled systems are not expected. However, satisfactory or acceptable results in terms of the robustness requirements are desired. From the simulation results, we can say that the robustness characteristics of the controlled systems are reasonable but in need of improvement at the same time. More detailed investigations of the robustness considerations are left for subsequent studies.

It is also an undeniable fact that it is important to develop the design considering the different dynamic characteristics in the design of a control system and to observe the achievement of the results obtained in a more realistic control setup [9], [11], [12], [14], [15], [17]. This work is one of the first steps of a long-running project. Accordingly, the main objectives are to investigate the benefits of different algorithms in the design of control systems, and to orient themselves to practical work out of the feasible outcomes. Hence, more realistic practices will be taken into account in future studies.

\section{CONCLUSIONS}

The main contribution of this study is to incorporate the PID control of the higher order oscillatory systems with the ABC algorithm. In this paper, the results of a PID controller design approach based on the use of $\mathrm{ABC}$ algorithm are presented for higher order oscillatory systems. In order to achieve this aim, the simulation results of different high order systems existing in the literature are comparatively given.

According to simulation results, it can notify that the ABC based PID tuning method can be easily and successfully applied to the higher order oscillatory systems. Furthermore, the interesting results of this method prove that they exhibit the competitive solutions to effectively achieve the presented control problem. Moreover, to obtain the high performance specifications from the PID controlled system, objective function used by the algorithm can be easily modified for control aims. By considering the time or frequency domain requirements of the system under control, performance parameters and/or robustness measurements can be inserted into the objective function. Thus, the computations needed to meet the goals of control design can be done without repeated use of the complex or time consuming mathematical operations, which is a significant advantage.

\section{REFERENCES}

[1] J. G. Ziegler, N. B. Nichols, "Optimum settings for automatic controllers", Transactions of ASME, vol. 64, pp. 759-768, 1942. [Online]. Available: http://dx.doi.org/10.1115/1.2899060

[2] G. H. Cohen, G .A. Coon, "Theoretical consideration of retarded control', Transactions of ASME, vol. 75, pp. 827-834, 1953.

[3] D. W. Pessen, "A new look at PID-controller tuning", Trans. ASME. Journal of Dynamical Systems Measures and Control, vol. 116, pp. 553-557, 1994. [Online]. Available: http://dx.doi.org/ $10.1115 / 1.2899252$

[4] M. Zhuang, D. P. Atherton, "Automatic tuning of optimum PID controllers", IEE Proc. Control and Applications, vol. 140, pp. 216 224, 1993. [Online]. Available: http://dx.doi.org/10.1049/ip- 
d. 1993.0030

[5] M. Morari, E. Zafiriou, Robust process control. Englewood Cliffs NJ: Prentice-Hall, 1989.

[6] D. E. Rivera, M. Morari, S. Skogestad, "Internal model control.4. PID controller design', Industrial and Engineering Chemistry Process Design and Development, vol. 25, pp. 252-265, 1986. [Online]. Available: http://dx.doi.org/10.1021/i200032a041

[7] W. K. Ho, O. P. Gan, E. B. Tay, E. L. Ang, "Performance and gain and phase margins of well-known PID tuning formulas", IEEE Trans. Control Systems Technology, vol. 4, pp. 473-477, 1996. [Online]. Available: http://dx.doi.org/10.1109/87.508897

[8] W. K. Ho, C. C. Hang, L. S. Cao, "Tuning of PID controllers based on gain and phase margin specifications", Automatica, vol. 31, pp. 497-502, 1995. [Online]. Available: http://dx.doi.org/10.1109/ ISIE.1992. 279722

[9] M. Huba, "Performance measures, performance limits and optimal PI control for the IPDT plant", Journal of Process Control, vol. 23 no. 4, pp. 500-515, 2013. [Online]. Available: http://dx.doi.org/ 10.1016/ j.jprocont.2013.01.002

[10] I. Mizumoto, D. Ikeda, T. Hirahata, Z. Iwai, "Control Engineering Practice Design of discrete time adaptive PID control systems with parallel feedforward compensator", Control Engineering Practice, vol. 18, no. 2, pp. 168-176, 2010. [Online]. Available: http://dx.doi.org/10.1016/j.conengprac.2009.09.003

[11] J. C. Jeng, W. L. Tseng, M. S. Chiu, "A one-step tuning method for PID controllers with robustness specification using plant stepresponse data", Chemical Engineering Research and Design, vol. 92 no. 3, pp. 545-558, 2014. [Online]. Available: http://dx.doi.org/ 10.1016/j.cherd. 2013.09.012

[12] M. N. Anwar, S. Pan, "A frequency response model matching method for PID controller design for processes with dead-time", ISA Transactions, vol. 55, pp. 175-187, 2015. [Online]. Available: http://dx.doi.org/10.1016/j.isatra.2014.08.020

[13] D. B. S. Kumar, R. P. Sree, "Tuning of IMC based PID controllers for integrating systems with time delay", ISA Transactions, vol. 63, pp. 242-255, 2016. [Online]. Available: http://dx.doi.org/10.1016/ j.isatra.2016.03.020

[14] D. Fister, I. Fister, R. Safaric, "Parameter tuning of PID controller with reactive nature-inspired algorithms", Robotics and Autonomous Systems, vol. 84, pp. 64-75, 2016. [Online]. Available: http://dx.doi.org/10. 1016/j.robot.2016.07.005

[15] J. C. Jeng, G. P. Ge, "Disturbance-rejection-based tuning of proportional-integral-derivative controllers by exploiting closed-loop plant data", ISA Transactions, vol. 62, pp. 312-324, 2016. [Online]. Available: http://dx.doi.org/10.1016/j.isatra.2016.02.011

[16] S. Srivastava, V. S. Pandit, "A PI/PID controller for time delay systems with desired closed loop time response and guaranteed gain and phase margins", Journal of Process Control, vol. 37, pp. 70-77, 2016. [Online]. Available: http://dx.doi.org/10.1016/j.jprocont. 2015.11.001

[17] Q. H. Seer, J. Nandong, "Stabilization and PID tuning algorithms for second-order unstable processes with time-delays", ISA Transactions, vol. 67, pp. 233-245, 2017. [Online]. Available: http://dx.doi.org/ $10.1016 /$ j.isatra.2017.01.017

[18] A. Bagis, "Determination of the PID controller parameters by modified genetic algorithm for improved performance', Journal of Information Science and Engineering, vol. 23, pp. 1469-1480, 2007.

[19] A. Bagis, A. Savascihabes, "Determination of the PID controller parameters by using binary and real coded genetic algorithm", International Symposium on Innovations in Intelligent Systems and Applications (ASYU 2008), Isparta, Turkey, pp. 198-202, 2008. (in Turkish).

[20] M. S. Saad, H. Jamaluddin, I. Z. M. Darus, "Implementation of PID controller tuning using differential evolution and genetic algorithms", Int. Journal of Innovative Computing, Information and Control, vol. 8, pp. 7761-7779, 2012.

[21] P. Wang, D. P. Kwok, “Optimal design of PID process controllers based on genetic algorithms", Control Engineering Practice, vol. 2 pp. 641-648, 1994. [Online]. Available: http://dx.doi.org/10.1016/ 0967-0661(94)90008-6

[22] A. Bagis, "Tabu search algorithm based PID controller tuning for desired system specifications', Journal of the Franklin Institute, vol. 348, pp. 2795-2812, 2011. [Online]. Available: http://dx.doi.org /10.1016/j.jfranklin.2011.09.001
[23] D. Karaboga, A. Kalinli, "Tuning PID controller parameters using tabu search algorithm', in Proc. IEEE Int. Conf. on Systems, Man and Cybernetics, Adiyaman, Turkey, pp. 134-136, 1996. [Online]. Available: http://dx.doi.org /10.1109/ ICSMC.1996.569754

[24] A. Bagis, A. Savascihabes, "PID tuning by using differential evolution algorithm for desired closed loop system response", Int Symposium on Innovations in Intelligent Systems and Applications (INISTA 2010), Kayseri, Turkey, pp. 170-174, 2010.

[25] D. Hai-bin, W. Dao-bo, Y. Xiu-fen, "Novel approach to nonlinear PID parameter optimization using ant colony optimization algorithm', Journal of Bionic Engineering, vol. 3, pp. 073-078, 2006. [Online]. Available: http://dx.doi.org/10.1016/S1672 6529(06)60010-3

[26] A. Alfi, H. Modares, "System identification and control using adaptive particle swarm optimization", Applied Mathematical Modelling, vol. 35, pp. 1210-1221, 2011. [Online]. Available: http://dx.doi.org/ 10.1016/j.apm.2010.08.008

[27] W. D. Chang, S. P. Shih, "PID controller design of nonlinear systems using an improved particle swarm optimization approach", Communications in Nonlinear Science and Numerical Simulation, vol. 15, pp. 3632-3639, 2010. [Online]. Available: http://dx.doi.org/ 10.1016/j.cnsns.2010.01.005

[28] J. Zhao, T. Li, J. Qian, “Application of particle swarm optimization algorithm on robust PID controller tuning', Lecture Notes in Computer Sciences, vol. 3612, pp. 948-957, 2005. [Online]. Available: http://dx.doi.org/10.1007/11539902_118

[29] D. Karaboga, B. Akay, "Proportional-integral-derivative controller design by using artificial bee colony, harmony search, and the bees algorithms", in Proc. IMechE Part I: J. Systems and Control Engineering, vol. 224, pp. 869-883, 2010. [Online]. Available: http://dx.doi.org/10.1243/09596518JSCE954

[30] A. Bagis, "Investigation of the performance of particle swarm optimization in the modeling of high order oscillatory systems", Automatic Control National Conf., Gebze, Kocaeli, Turkey, pp. 168173, 2010. (in Turkish)

[31] A. Bagis, H. Senberber, "Modeling of higher order systems using artificial bee colony algorithm', An International Journal of Optimization and Control: Theories \& Applications, vol. 6, no. 2, pp. 129-139, 2016. [Online]. Available: http://dx.doi.org/10.11121 /ijocta.01.2016.00298

[32] D. Karaboga, B. Akay, "A powerful and efficient algorithm for numerical function optimization: artificial bee colony (ABC) algorithm', Journal of Global Optimization, vol. 39, pp. 459-471, 2007. [Online]. Available: http://dx.doi.org/10.1007/s10898-0079149-x

[33] D. Karaboga, B. Akay, "A comparative study of artificial bee colony algorithm', Applied Mathematics and Computation, vol. 214, pp. 108-132, 2009. [Online]. Available: http://dx.doi.org/10.1016/ j.amc.2009. 03.090

[34] R. C. Eberhart, J. Kennedy, "A new optimizer using particle swarm theory", in Proc. Sixth Int. Symposium on Micromachine and Human Science, Nagoya, Japan, 1995, pp. 39-43. [Online]. Available: https://doi.org/10.1109/MHS.1995.494215

[35] J. Kennedy, R. C. Eberhart, "Particle swarm optimization", in Proc. IEEE Int. Joint Conf. on Neural Networks; Perth, West Australia, pp. 1942-1948, 1995. [Online]. Available: https://doi.org/10.1109/ ICNN.1995.488968

[36] A. Karimi, D. Garcia, R. Longchamp, "PID controller tuning using Bode's integrals", IEEE Trans. Control Systems Technology, vol. 11 pp. 812-821, 2003. [Online]. Available: http://dx.doi.org/ 10.1109/TCST.2003.815541

[37] G. M. Malwatkar, S. H. Sonawane, L. M. Waghmare, "Tuning PID controllers for higher-order oscillatory systems with improved performance', ISA Trans., vol. 48, pp. 347-353, 2009. [Online]. Available: http://dx.doi.org/10.1016/j.isatra.2009.04.005

[38] Q. G. Wang, T. H. Lee, H. W. Fung, Q. Bi, Y. Zhang, “PID tuning for improved performance', IEEE Trans. Control Systems Technology, vol. 7, pp. 457-465, 1999. [Online]. Available: http://dx.doi.org/10.1109/87.772161

[39] MathWorks, Control system toolbox user's guide. R2014a. The MathWorks, Inc., 2014.

[40] R. C. Dorf, R. H, Bishop, Modern control systems-8th edt. AddisonWesley Longman, Inc., 1998.

[41] W. S. Levine, The control handbook. CRC Press LLC, USA, 1996. 